\section{Cesium interaction with aluminosilicates: how does the specificity of the structure affect sorption?}

\author{
IRINA TONYAN ${ }^{1}$, ANNA SEMENKOVA, PHD ${ }^{1}$, ANNA \\ ROMANCHUK $^{1}$, VICTORIA KRUPSKAYA ${ }^{2}$ AND STEPAN \\ KALMYKOV $^{1}$
}

${ }^{1}$ Lomonosov Moscow State University

${ }^{2}$ Institute of Geology of Ore Deposits, Petrography, Mineralogy and Geochemistry (IGEM) RAS

Presenting Author: iton612@yandex.ru

The disposal of radioactive waste (RW) involves the creation of a protective system of engineering barriers designed to ensure the safety of the storage facility for long periods. For these purposes, it is proposed to use barrier materials that prevent the entry of radionuclides into the environment due to the high sorption capacity and low water permeability. Bentonite clays, whose properties are provided by the presence of smectite group minerals, are considered to be the most promising material.

In this work, we compared Cs behavior during its interaction with various aluminosilicates: smectite, kaolinite, illite, and zeolite. During this study we made experiments with natural bentonite clays of different deposits: non-widely studied previously (Khakassia, Zyryanskiy deposit, Dinosaur deposit) as well as widely studied samples MX-80 (USA, Wyoming), KunipiaF (Japan), FEBEX (Spain). The cesium sorption was studied in a wide $\mathrm{pH}$ range and concentrations $\left[\mathrm{Cs}^{+}\right]=10^{-14}-10^{-2}$ M.

The interaction of cesium occurs by the mechanism of ion exchange:

$\equiv \mathrm{XNa}+\mathrm{Cs}^{+}=\equiv \mathrm{XCs}+\mathrm{Na}^{+}$,

where $\equiv \mathrm{X}$ is the sorption centers.

We found the significant differences in cesium behavior on the studied samples. Decrease in cesium sorption in the row illitemontmorillonite zeolite-kaolinite in the whole range of concentrations studied was observed. Despite differences in structure, similar sorption dependencies were obtained for samples MX-80 and zeolite.

For a number of bentonites (FEBEX, Zyryanskiy, Dinosaur, Dash-Salakhinskiy and Khakassia deposits,) 2 plateaus on Cs sorption isotherms can be observed, that indicates the existence of different types of sorption sites. MX-80 and KunipiaF have a similar mineral composition, but only one sorption site can be found, and the sorption values are significantly lower. Also significant differences observed for cesium sorption on samples 10-Hutor and Dinosaur that have similar composition.

The significant difference in sorption properties of bentonite samples with similar composition should be noted. This may be due to the influence of the fine structure of the sample.

The correlation between the sorption of trace cesium concentrations and the charge magnitude of the clay layer was revealed.

This work was supported by the Russian Science Foundation (project 20-73-00135).

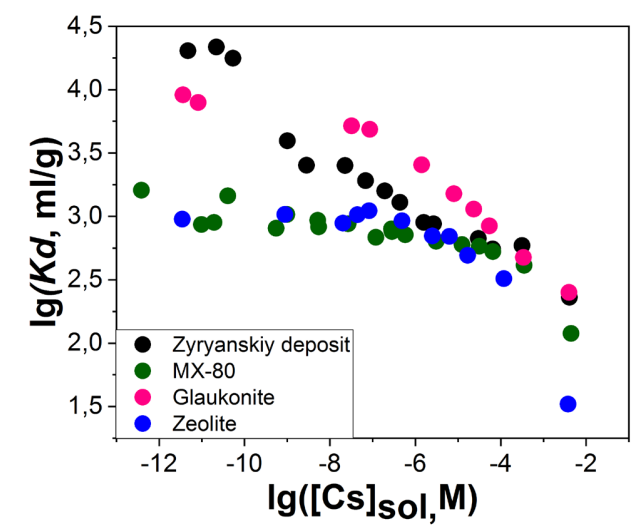

